NASA Technical Memorandum 89924

AIAA-87-1950

\title{
Langmuir Probe Surveys of an Arcjet Exhaust
}

Lynnette M. Zana

Lewis Research Center

Cleveland, Ohio

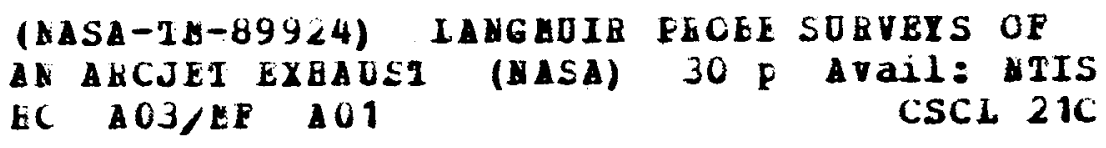

N87-228C7

$\begin{array}{ll}63 & \text { Unc1as } \\ j / 20 & 0077503\end{array}$

Prepared for the

23rd Joint Propulsion Conference

cosponsored by the AIAA, SAE, ASME, and ASEE

San Diego, California, June 29-July 2, 1987 


\title{
LANGMUIR PROBE SURVEYS OF AN ARCJET EXHAUST
}

\author{
Lynnette M. Zana \\ National Aeronautics and Space Administration \\ Lewis Research Center \\ Cleveland, Ohto 44135
}

\begin{abstract}
SUMMARY
Electrostatic (Langmuir) probes of both spherical and cylindrical geometry have been used to obtain electron number density and temperature in the exhaust of a laboratory arcjet. The arcjet thruster operated on nitrogen and hydrogen mixtures to simulate fully decomposed hydrazine in a vacuum environment with background pressures less than $0.05 \mathrm{~Pa}$.

The exhaust appears to be only slightly fonized (less than 1 percent) with local plasma potentials near faclitity ground. The current-voltage characteristics of the probes indicate a Maxwellian temperature distribution. Plume data are presented as a function of arcjet operating conditions and also position in the exhaust.
\end{abstract}

\section{INTRODUCTION}

An arcjet thruster is an electrothermal propulsion device which heats a propellant by means of a high temperature arc discharge and then expands the hot gas through a nozzle to produce thrust. Because it offers relatively high specific impulse at moderate thrust levels, the arcjet is an attractive candidate for auxiliary propulsion applications. At present, the power realistically available for satellite propulsion requirements is between 0.5 and $1.5 \mathrm{~kW}$. When operated with storable propellants at these power levels, the arcjet can provide specific impulses of $400 \mathrm{sec}$ and higher, offering potentially large benefits for mission applications such as stationkeeping on communication satellites. Recently, efforts have been inftiated, both at MASA and in industry, to demonstrate the technology readiness of a low power $(700$ to $1500 \mathrm{~W})$, dc arcjet with storable propellants for such missions. Technology issues currentiy being addressed include arc start-up and stablitity, performance, 11fetime, power processing, and spacecraft integration (refs. 1 to 4 ). In conjunction with the above efforts, research programs to investigate the plumes of arcjet thrusters have also begun.

A detalled description of the arcjet exhaust is required for not only a fundamental understanding of the plume character but also an accurate assessment of the potential impacts that the plume may have on thruster performance and to the spacecraft upon integration. The primary integration concern is the potential impact due to EMI or induced environment effects on communications. Thrust losses and thermal loading may also be of concern depending on the spacecraft/thruster configuration. The exhaust of an arcjet can be described as a low density, high temperature, supersonic flow field that is silghtly ionized (less than a few percent) and chemically reactive in nature. Because of this complex combination of plume properties and also the fact that arcjet nozzles are typically very small, it is difficult to obtain local, quantitative information on the flow field with conventional probe techniques. 
However, experimental investigations of the arcjet exhaust have been conducted previously. In the early 1960's, Plasmadyne Corporation (ref. 5) measured the shape and radiation intensity of a $1 \mathrm{~kW}$, hydrogen arcjet using motion picture photography and a thermop 11 e radiometer. Additionally, McDonnell Aircraft Corporation (refs. 6 and 7) applied a varlety of diagnostic techniques near the exit plane of high power (10 to $50 \mathrm{~kW}$ ), hydrogen arcjets. The measurements included: probe surveys to obtain electron number density and temperature, mass flux, impact pressure, and stagnation enthalpy profiles; photometric techniques to measure exhaust velocity; and spectrophotometer observations to determine excitation temperature. Although a great deal of effort was expended in developing the above-mentioned techniques, much of the information gained in the previous experiments was qualitative in nature and not directly transportable to present analyses.

Lastly, Limbaugh (ref. 8) determined the excited state density distribution within the freely expanding plume of an argon arcjet $(150 \mathrm{~A}, 20 \mathrm{~V})$. He found the energy distribution did not fit a Maxwell-Boltzmann population of excited state number densities and that the electron temperature was much greater than the static gas temperature. Using spectral line absorption and emission measurements, electron number densities of 1 to $4 \times 10^{14} / \mathrm{cm}^{3}$ were obtained at temperatures of approximately $0.6 \mathrm{eV}$.

This paper presents initial results in the experimental investigation of low power, dc arcjet plumes. The primary research goals are: to obtain plasma number density and temperature as a function of position and operating condition; to evaluate vacuum facility pressure effects on the measurements; and, ultimately, to assess the plume impacts, subject to the above experimental results. For example, once the plume electron number density distribution is known, estimates of the impacts to communications signals transmitted through the plume can be calculated. The Langmuir probe is the primary diagnostic technique to be used in this investigation.

The first portion of this paper provides a discussion of the theory and operation of Langmuir probes for measuring plasma properties. Details of probe design and fabrication, along with factors which govern the data analysis, will be provided. The experimental hardware and vacuum factlitty for the probe surveys are also discussed.

The major portion of this paper presents initial experimental data in the plume of a low power, dc arcjet. The arcjet used in this study is a laboratory thruster, operating on a propellant mixture of nitrogen and hydrogen, to simulate fully decomposed hydrazine. Data are presented as a function of position in the exhaust and also arc power. Comparisons are made between probes of different size and geometry. Finally, recommendations for future work are proposed.

\section{NOMENCLATURE}

A probe surface area, $\mathrm{m}^{2}$

$A^{\prime}$ wetted surface area of spherical probe $\left(2 \pi R_{p}^{2}\right), m^{2}$

$A_{e}$ nozzle exit area, $m^{2}$ 


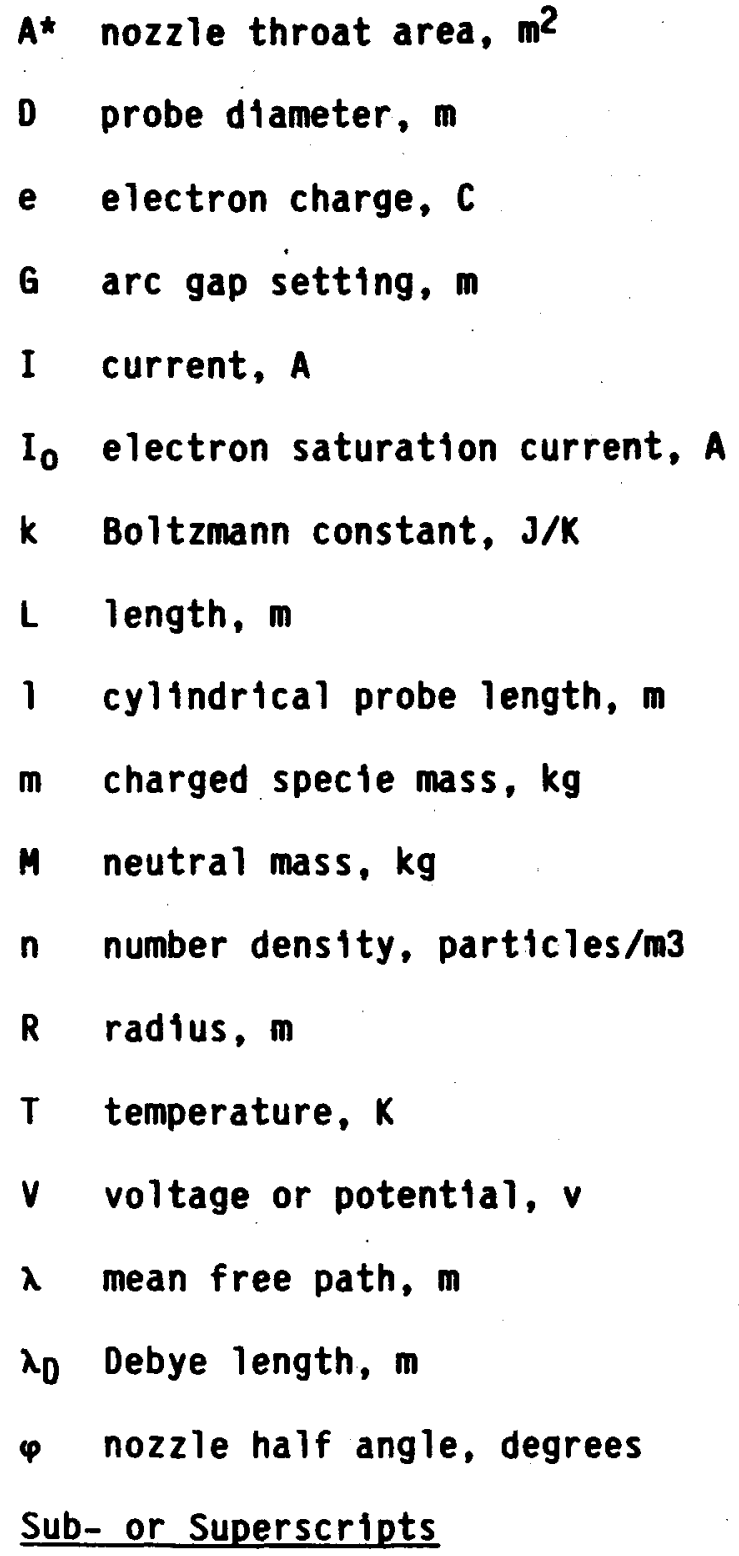
a arc
c constrictor
e electron
f floating
1 Ion
n neutral particles
p probe
$\infty \quad$ plasma 


\section{ANALYSIS}

The Langmulr probe is one of the most widely used and accepted means of obtaining information on plasma properties. In its simplest form, it consists of a small conductive element and an associated power supply which is capable of biasing the probe to various voltages, both positive and negative, with respect to the plasma to be investigated. The current drawn to the probe as a function of voltage, or the "probe characteristic," yields two primary quantities, electron number density and electron temperature.

The theory that governs interpretation of the probe characteristic is quite complicated. Excellent reviews of general probe theory in both the presence and absence of collisions may be found in references 9 to 11 . Laframboise (ref. 12) established both spherical and cylindrical probe theory in a collisionless, stationary plasma. Further, the application of the Langmuir probe to flowing, collisionless plasmas has been investigated by French (ref. 13), Sonin (ref. 14), and Clayden (ref. 15).

An ideal probe characteristic is 1 llustrated in figure 1 . If the probe is biased sufficiently negative with respect to the plasma potential, all electrons will be repelled and only tons will be collected by the probe. A layer of positive charge, called an "ion sheath," builds up around the probe. Its formation is primarily dependent upon the ion mass and temperature. As the probe voltage is increased positively, electrons are also attracted to the probe surface. At the floating potential, $V_{f}$, the magnitude of the fon and electron currents are equal. Increasing the probe voltage further draws still more electrons to the probe. If the velocity distribution of electrons in the plasma is Maxwellian, this transition region will be marked by an exponential increase in electron current. At some point, $V_{\infty}$, the probe potential is equal to that of the plasma. There is still a small ion contribution at $V_{\infty}$. Biasing the probe beyond $V_{\infty}$ causes electrons to be accelerated toward the probe and ions to be repelled. In this region, the excess of negative charge near the probe surface again forms a sheath. As long as the probe size is large in comparison with the Debye length, the sheath thickness may be assumed to be relatively constant with potential and equal to that of the probe dimensions.

Provided that the probe does not disturb the plasma (or the macroscopic flow field) and that the electrons exhibit a Maxwellian distribution, interpretation of the characteristic is reasonabiy straightforward. In the transition region, the electron current collected by the probe will be given by

$$
I_{e}=A_{p} \text { en } \sqrt{\frac{k T_{e}}{2 \pi m_{e}}} \exp \left[\frac{-e\left(V_{p}-V_{\infty}\right)}{k T_{e}}\right]
$$

Taking the logarithm of equation (1) and differentiating with respect to the probe voltage gives

$$
\frac{d}{d V}\left(\ln I_{e}\right)=\frac{-e}{k T_{e}}
$$

Consequently, the slope of a semi-log plot of electron current as a function of probe voltage yields electron temperature. Plasma potential is generally obtained by extrapolating the linear portion of the transition and 
electron accelerating regions of this same plot. At plasma potential, using a thin sheath analysis,

$$
I_{0}=e A_{p} n_{e} \sqrt{\frac{k T_{e}}{2 \pi m_{e}}}
$$

The saturation electron current, $I_{0}$, is the electron current at plasma potential $\left(V_{p}=V_{\infty}\right)$. Rearranging equation (3) gives the electron number density in terms of known quantities, as,

$$
n_{e}=\left(3.73 \times 10^{13}\right) \frac{I_{0}}{A_{p}} \sqrt{\frac{11600}{T_{e}}}
$$

The above analysis is predicated on the assumption that

$$
\lambda \gg R p \gg \lambda_{D}
$$

where the Debye length is

$$
\lambda_{D}=6.9 \times 10^{3} \sqrt{\frac{T_{e}}{n_{e}}}
$$

and $\lambda$ represents the collision mean free paths. A discussion of the relevant collision phenomena and the associated mean free paths may be found in appendix $A$.

For low density plasma flows, previous investigators (refs. 13 and 14) have used cylindrical probes allgned with the flow streamlines to avoid the effects of bulk fluld (neutral) motion. Spherical probes are promising because they do not have this alignment constraint. Clayden (ref. 15) has obtained reasonable results using spherical probes in a low density plasma jet; however, a "wetted" current collection area (one-half of the spherical surface area) was used in the calculation of $n_{e}(e q .(4))$. This modiffcation was made to account for the existence of a wake behind the probe which electrons are unable to penetrate.

\section{APPARATUS}

\section{Langmuir Probes}

Langmuir probes of both spherical and cylindrical geometry were used in this investigation. Figure 2 displays sketches of the stationary and movable probes. The stationary probes were made from carbide steel ball bearings with a radius of $0.562 \mathrm{~cm}$. Each bearing was welded to a $0.76 \mathrm{~mm}$ tungsten wire. Stainless steel tubing was used to support the probe and also serve as an electrostatic shield. The ball bearing was located approximately 4 to 5 support diameters in front of the tube. Alumina tubing was used as the insulator between the wire and the shield. It was recessed $0.16 \mathrm{~cm}$ from the end of the stainless shield. Kapton tape covered the shield in the vicinity of the sphere. A larger spherical probe (radius of $0.794 \mathrm{~cm}$ ) was installed at the off-axis stationary location for later measurements. 
The support assembly for the movable probes had a U-shaped geometry because they had to sweep across the plume. The spherical probe was a carbide steel ball bearing of radius $0.316 \mathrm{~cm}$. The cylindrical probe was made of tungsten wire of radius $0.114 \mathrm{~cm}$ and length $0.952 \mathrm{~cm}$. Both probes used ceramic insulation as the main support at the location of the measurement.

Figure 3 displays an electrical schematic of the probe blas circuitry. The bias supply could linearly ramp the probe voltage from a preselected negative value to a positive value over a five second time period. The ramp voltage ranges which could be selected were: -10 to $+10 \mathrm{~V},-50$ to $+50 \mathrm{~V}$, and -100 to $+100 \mathrm{~V}$. The probe voltage was measured by a high impedance divider network while the probe current was obtained by measuring the voltage across a $1.00 \Omega$ resistor. The two signals were sent through isolation ampliffers to an $X-Y$ recorder. Because the current collected by the probe increases exponentially near plasma potential, the probe bias supply ramped slowly enough so that the $X-Y$ recorder could keep up. As long as the arcjet exhibited a stable operating condition, the dc current change with time varied by less than 1 percent when the probe was biased at large positive or large negative voltages with respect to plasma potential. However, a slight difference in anode potential could have a marked effect in current collected near plasma potential. Thermal and time dependent offsets in the amplifiers were zeroed out prior to each probe sweep. The estimated uncertainty in the current measurements was approximately $0.3 \mathrm{~mA}$.

\section{Arcjet Thruster}

A photograph of the laboratory arcjet used in this investigation is shown in figure 4. The main body of the the thruster is stainless steel with boron nitride insulation. The thruster discharge region incorporates a vortex stabilized, constricted arc design. The tungsten insert shown in the figure serves both as anode and expansion nozzle. Major geometric characteristics of the arc constrictor and nozzle are found in table I. Reference 1 provides a complete description of the major design features of this thruster.

Arcjet power was provided from a well regulated, pulse width modulated supply (ref. 2). The design consists of a starting circuit which provides brief, high voltage pulses to initiate the arc discharge via Paschen breakdown and a second circult for a well regulated, current-controlled mode of operation. In normal operation, arcjet current ranged from 8 to $12 \mathrm{~A}$, although most of the tests reported herein were conducted at $11 \mathrm{~A}$. The arc current was measured with a commercially avallable current probe whlle arc voltage was measured with a high impedance divider network. The entire system was isolated with anode potentials, during arcjet operation, typically near facility ground due to plasma bleed. The thruster floating voltage, anode to ground, was monitored with a 10 Ms digital meter.

Typically, the arcjet was operated on a $2: 1$ volume ratio of nitrogen to hydrogen to simulate fully decomposed hydrazine. The two gases were stored separately and mixed upstream of the thruster inlet. Digital flow meters, calibrated for the specific gas type, were used in conjunction with precision needle values to control individual volume flow rates. The full-scale reading of each digital meter was $5.00 \mathrm{~s} / \mathrm{pm}$. The mixed propellant. was fed to the thruster through a flexible feed tube. Unless otherwise noted, the mass flow rate of the thruster using the $\mathrm{N}_{2}: \mathrm{H}_{2}$ mixture was $0.045 \mathrm{~g} / \mathrm{sec}(2.00 \mathrm{SLPM} \mathrm{N}$ 
and 4.00 SLPM $\mathrm{H}_{2}$ ). Additionally, there were a number of initial plume measurements made using only pure nitrogen as the propellant. The typical mass flow rate for these nitrogen-only tests was $0.061 \mathrm{~g} / \mathrm{sec}$.

\section{Instrumentation}

Measurements of the dc arc current and voltage, and the premixed propellant volume flow rates were monitored by a chart recorder. Isolation amplifiers and shielded cables were used for all signal processing. The real-time transients of the arc current were also monitored using an analog osc1lloscope with a differential amplifier input. Lastly, the thruster inlet pressure, facility pressure, and thruster floating voltage were recorded manually at regular intervals. Typical arcjet thruster operating conditions and performance characteristics are listed in table II.

\section{Test Facility and Experimental Set-up}

The Langmuir probe surveys were conducted in a $1.5 \mathrm{~m}$ diameter by $5 \mathrm{~m}$ long vacuum facility at NASA Lewis Research Center. The tank is equipped with four 011 diffusion pumps and, for the the experimental conditions described herein, maintained a background pressure less than $5 \times 10^{-2} \mathrm{~Pa}\left(4 \times 10^{-4}\right.$ Torr).

The arcjet thruster, as displayed in figure 4, was mounted on a cradle assembly at the end of a push/pull rod that could be extended we 11 into the tank environment. Here, it rested on a fixed table to ensure that the thruster position would be stable and repeatable from one test date to the next. The thruster exhausted along the tank centerline as shown in figure 5 . The two stationary, spherical probes were mounted inside the tank at the locations denoted in the figure. One probe was located on the plume centerline, $30.5 \mathrm{~cm}$ downstream of the thruster exit plane, while the other probe was at the same axtal plane but $15.2 \mathrm{~cm}$ off centerline. The movable probes were positioned in the plume using a push/puli rod entering through a side port entrance. Probes of both spherfcal and cylindrical geometry were used. The only rotation available with this arrangement was in the vertical plane; therefore, cylindrical probe measurements could only be obtained on the plume centerline. The spherical probes were used to obtain radial profiles of the arcjet plume properties. The axial distance for these measurements was $18.4 \mathrm{~cm}$.

\section{PROCEDURE}

The positions of the thruster and the probes were fixed at their predetermined locations prior to the experiment and every time a probe was changed. The Langmuir probes were cleaned chemically before placement in the tank. Subsequent cleaning at the beginning of each test period was accomplished by fon sputtering. The probes were biased to a large negative potential for several minutes while the thruster was operating. Generally, the thruster was allowed to run for 20 to 30 min after the arc discharge was initiated so that it could reach a steady-state condition. Subsequent changes to thruster operation, such as variations in arc current, required only a few minutes for the arcjet to reach a new steady-state operating condition. 


\section{Nitrogen-Hydrogen Mixture Operation}

The bulk of data presented were taken with the arcjet operating on a 2:1 mixture ratio of hydrogen and nitrogen, as previousiy specified. The Langmuir probe drive supply was tied to anode potential and the probes were ramped 1inearly through a voltage range of -10 to $+10 \mathrm{~V}$. Since the greatest change in current collected by the probe varles over a short voltage range, probe data were taken with the $X-Y$ recorder at two different sensitivities.

Using the stationary probes, probe data were obtained at the two downstream locations as a function of arcjet operating condition. With the mass flow constant at $0.045 \mathrm{~g} / \mathrm{sec}$, the arc current was varied from 9 to $12 \mathrm{~A}$. Typical arc voltages for these measurements ranged from 100 to $105 \mathrm{~V}$, although sometimes excursions between 92 and $110 \mathrm{~V}$ were noted for a given arc current and a fixed flow rate. Since the arc voltage is primarily dependent upon the manner in which arc attachment is made at the anode, slight variations in arc voltage are not unusual. As long as the arcjet exhibited a stable operating condition, with a stable arc voltage and a nonwavering plume, plume data could stili be obtained. Slight voltage excursions do not significantly impact thruster performance (ref. 16).

Plume data were often taken under similar arcjet operating conditions on different test dates and at different times during a given test date to verify repeatability and consistency of the measurements. Also, data were taken with probes of different size and geometry. In all cases, the arcjet operating condition was established by setting the arc current (usually 11 A) and mixture flow rate $(0.045 \mathrm{~g} / \mathrm{sec})$ to the same values.

A radial profile was also obtained with a movable probe of spherical geometry. It took a period of approximately $15 \mathrm{~min}$ to obtain all of the radial data. During that time the arcjet remained stable in terms of its operating characteristics, including arc voltage. Nonetheless, stationary probe data were obtained before and after the the radial test sequence to ensure consistent plume characteristics.

\section{Nitrogen Only Tests}

A limited amount of experimental data was obtained with the arcjet operating on pure nitrogen gas. The arc current for the data presented was $10 \mathrm{~A}$ at a flow rate of $0.061 \mathrm{~g} / \mathrm{sec}$. The Langmuir probes were tied to cathode common, which typically ran at a potential of $60 \mathrm{~V}$ below facility ground. The probes ramped through a -100 to $+100 \vee$ sweep at two different recorder sensitivities.

\section{Experimental Data Reduction}

A computer code originally developed at the Colorado State University (ref. 17) was used to calculate the plume parameters from the V-I characteristic. Probe electron current (total probe current minus ion contribution) and associated voltage pairs were input in the program. A least squares fit was used to extrapolate the linear portions of the retarding and accelerating regions of the probe characteristic. Plasma potential was defined as the point at which the two extrapolated lines intersected. The computer code relied on an estimate of plasma potential and also the voltage at which the accelerating 
portion of the characteristic began. Consequently, the data were first plotted graphically to obtain reasonable estimates of these values. The plasma potential input was chosen as the value of probe voltage at which the slope of the logarithmic current versus voltage first deviated from linearity.

\section{RESULTS ANO DISCUSSION}

The first portion of this section discusses typical Langmuir probe characterfstics for arcjet operation on pure nitrogen and also nitrogen-hydrogen mixtures. The general character of the plume under the two different modes of operation is described, along with estimates of the uncertainty of the measurements. Comparisons are made between probes of different size and geometry. Lastly, the exhaust of an arcjet operating on mixtures is described in terms of electron number density and temperature as a function of arcjet operating condition and also location in the plume.

\section{Representative Probe Characteristics}

Figures 6 and 7 display representative $V-I$ characteristics for the spher $1-$ cal probes located $30.5 \mathrm{~cm}$ downstream of the thruster exit on the plume centerline. In the two figures, the logarithm of the current collected by the probe (total probe current minus ion contribution) is plotted against the probe voltage with respect to arcjet common. The different symbols in the figures denote the $X-Y$ recorder sensitivities.

In figure 6, the arcjet was operating on pure nitrogen propellant at a mass flow rate of $0.06 \mathrm{~g} / \mathrm{sec}$. The arc current was $10 \mathrm{~A}$ with a corresponding arc voltage of $63 \mathrm{~V}$. The anode potential is approximately $3 \mathrm{~V}$ above facility ground.

The linearity over three decades of current change indicates a Maxwellian distribution of electron velocities. Applying the foregoing analysis, extrapolation of the linear portions of the transition and accelerating regions yields an electron number density of $1.9 \times 1010 / \mathrm{cm}^{3}$ at a temperature of $0.86 \mathrm{eV}$. The estimated uncertainty in the number density calculation is about 8 percent, primarily due to the uncertainty in the slope determination $( \pm 0.10 \mathrm{eV})$. The plasma potential appears relatively close to that of anode potential, at $2 \mathrm{~V}$.

Similarly, figure 7 displays the characteristic for the same probe with the arcjet operating on nitrogen-hydrogen mixtures. In this figure, the probe voltage is referenced to the arcjet anode, which is again fairly close to facllity ground, at $+0.8 \mathrm{~V}$.

Even though the arc power is considerably higher in this case, the plume exhibits a much lower concentration of charged species. Because the current collected by the probe is linear over at least two decades, a Maxwellian distribution is assumed, and the electron density is calculated at $3.5 \times 109 / \mathrm{cm}^{3}$. However, the estimated uncertainty is 14 percent, since overall current values are considerably smaller than in the previous case. Also, the plume electron temperature is silightly cooler with the arcjet operating on mixtures. The measured electron temperature is $0.51 \mathrm{eV} \pm 0.10 \mathrm{eV}$. The Debye length, based on the measured values of $T_{e}$ and $n_{e}$, is $9.0 \times 10^{-3} \mathrm{~cm}$, a factor of sixty smaller than the probe radius, so the thin sheath analysis is applicable. Values of 
the charged-charged and charged-neutral mean free paths are at least one to two orders of magnitude larger than the probe radius at this measurement location. Estimates of the relevant mean free paths for the various collision phenomena may be found in table Al.

Variation in electron number density in the plume is due to the combined effect of gas dynamic expansion and also recombination. Recombination may be the result of radiative, dissociative, or three body collisions in the exhaust. The reason for the lower concentration of electrons in the plume of the arcjet operating on mixtures is presumably due to the large amount of hydrogen in the flow. Hydrogen, although it has the same ionization potential as nitrogen, has significantly higher electron-ion recombination coefficients. Consequently, although the collision frequencies in the plume of the arcjet operating of pure nitrogen are probably higher than in the case of mixtures, as there are higher neutral densities, a smalier percentage of the charged species recombine. The data obtained thus far is insufficient to fully document the relative magnitudes of collisional effects on recombination in the arcjet exhaust.

\section{Plume Data With Arcjet Operation on Mixtures}

All of the experimental data presented herein apply to arcjet operation with nitrogen and hydrogen mixtures to simulate decomposed hydrazine. Figure 8 displays electron number density values obtained with the stationary spherical probes. The data in figure $8(a)$ were taken on the plume centerline, $30.5 \mathrm{~cm}$ downstream of the thruster exit, whlle the data in figure $8(b)$ were taken at the same axial station but $15.2 \mathrm{~cm}$ off axis. Because a set arc current did not always give a consistent arc voltage, the calculated electron number density values are plotted as a function of arc power. The various symbols, as described in the figures, denote the different arc current settings. The estimated uncertainty in the data is 14 percent. Both figures display an increase in measured electron number density with arc power. Further, within the limitations of the probe technique, there is a reasonable consistency in the measured values of electron number density for a given arc current and voltage. For example, the closed symbol data taken at $10 \mathrm{~A}$ (fig. 8(a)) were taken during the same test, but at time intervals of at least 40 to $80 \mathrm{~min}$ apart. Further, the open symbol data point at 10 A was taken during a different test date but at approximately the same operating condition.

Figure 9 displays corresponding values of electron temperature for the stationary probe on the plume centerline. A systematic variation in temperature with arc current, voltage, or power is not evident, as the scatter in the data is fairly large. One might expect an increase in electron temperature with arc current, because the core temperature increases with current but, within the scatter of data found, this trend was not directiy apparent, as shown figure 9. However, it should be noted that the average temperature for measurements at $10 \mathrm{~A}$ is $0.53+0.10 \mathrm{eV}$, while at $11 \mathrm{~A}$, the average value is slightly higher at $0.64+0.10 \mathrm{eV}$.

\section{Variations in Probe Size and Geometry}

Plume data were taken with spherical probes of two different radil at the off axis, stationary location. Referring back to figure $8(b)$, there is excellent agreement in measured number density between the two probes under similar 
arcjet operating conditions. However, differences do exist in the measured electron temperatures. Table III provides specific information on individual data points.

A comparison of probe geometry was also made using the movable probe arrangement. Table IV presents individual probe data taken with the spherical and cylindrical probes at an axial distance of $18.4 \mathrm{~cm}$, on the plume center1ine. The electron temperatures are relatively consistent independent of the probe geometry but there is a definite increase in measured electron number densities for the spherical probe data. There is an increased uncertainty in the cylindrical probe data due to the very small amount of current drawn to the probe with bias voltage, but this in itself does not account for the discrepancy. Clayden (ref. 15) also found that spherical probes gave higher values of electron number densities than cylindrical shapes. It should be mentioned that a wetted surface area (one half of the spherical surface area) was used to interpret the spherical probe data. While this modification is made to account for the existence of a wake behind the probe which electrons are unable to penetrate (ref. 15), it may represent an a source of error in interpretation of data and certainiy warrants further investigation.

\section{Radial Plume Measurements}

A spherical probe was used to obtain a radial profile at an axial distance of $18.4 \mathrm{~cm}$ downstream of the thruster exit plane. Figure 10 presents the measured electron number density and temperature variation as a function of angle off plume centerline. As shown in figure 10(a), the measured number density decreases exponentially. The measured number density is approximately one half of the centerline value at an angle of $25^{\circ}$.

Figure 10 (b) presents electron temperature values based on the same set of measurements. There is no apparent variation in temperature within the radial distance off centerline $(\sim 23 \mathrm{~cm}$ maximum). These findings are similar to previous investigations (refs. 7 and 15). Even though the neutral gas temperature varies markedly with radial position, the electrons do not follow this pattern because of the poor energy exchange between the heavy particle neutrals and the highly mobile electrons (ref. 14).

\section{CONCLUDING REMARKS}

Langmuir probes of spherical and cylindrical geometry have been used to investigate the exhaust of a low power, dc arcjet thruster operating on nitrogen and hydrogen mixtures. Preliminary measurements with a spherical probe located $\sim 30 \mathrm{~cm}$ downstream of the thruster exit plane have indicated electron number densities on the order of $3 \times 109 / \mathrm{cm}^{3}$ at a temperature of $0.5 \mathrm{eV}$. This low concentration of electrons represents less than 1 percent of the total centerline density. An increase in the measured number density was observed with increased arc power.

A radial proftle at a distance of $18 \mathrm{~cm}$ downstream of the thruster was also obtained. The measured electron density profile decreased exponentially as a function of angle off centerline while the values of electron temperature exhibited no systematic variation with radial position. Probes of different 
size yielded consistent results, within the limftations of the existing measurement technique. However, a spherical probe gave higher measured electron densities than did a cylindrical shape, although the measured electron temperatures agreed.

It is apparent that detalled plume surveys of the arcjet exhaust will require probes of different size and geometry. In some regions it may be impossible to avoid the use of complex probe theories in order to interpret the probe characteristics. The macroscopic effects of the flow field on sheath formation (thick sheath analysis) and also the application of continuum methods require investigation. Further, although the spherical probe does not require alignment with flow streamilines, there is some question about the true current collection surface area near plasma potential.

To obtain better measurement of ion saturation current, it will be necessary to obtain greater accuracy in the current collected by the probe, probabiy down to the tens of micro-amperes. This will permit information on ion temperatures and densities to also be extracted from a single probe characteristic. Lastiy, vacuum facility pressure effects play a large role in the region where meaningful information can be obtained. The effects of facility pressure on the gas dynamic expansion and also the recombination rates will require detailed investigation.

\section{ACKNOWLEDGMENTS}

The author wishes to acknowledge the assistance of Mr. Thomas $W$. Haag and Dr. Francis $M$. Curran in the integration and maintenance of the laboratory arcjet as well as helpful discussions with Mr. James S. Sovey in the implementation of the diagnostic technique. Also, the technical support of Mr. Craig N. Horak and Mr. Charles A. Reuger are deeply apprectated. 


\section{APPENDIX A - COLLISION PHENOMENA}

In order to apply collisionless theory to the Langmuir probe characteristic, it is important that both the probe radius and the Debye length are small in comparison with the representative mean free paths. In a plasma where the percentage of ionization is small, 1.e., less than a few percent, collisions between charged species and also neutrals become relevant. Tables A1 and A2 list order of magnitude estimates of the most important mean free paths for the two primary plume centerline measurement locations. The collisions between charged species were calculated using Spltzer's relation (refs. 14 and 18) while the mean free paths between neutrals were calculated using gas kinetic theory. Electron-neutral collisions (both elastic and inelastic) were calculated using Maxwellian averaged cross sections (ref. 19) based on emperical data for the collision cross sections as a function of electron velocity. Ionneutral mean free paths were estimated using the assumption that $\lambda_{\text {in }}$ is approximately one-third of $\lambda_{n n}$ (ref. 14).

The available experimental data were used to obtain necessary estimates of charged specte number densities at the two measurement locations. Reasonable values of the neutral densities, of both molecular and dissociated species, were not easily attainable. A detalled plume analysis requires a complete description of the nozzle flow field as input. The highly viscous arcjet nozzle flow, coupled with the unwieldy size of the nozzles, precludes the immediate adaptation of conventional nozzle flow computational techniques. Further, the nonequilibrlum nature of the flow, in conjunction with the fact that a considerable amount of heat addition occurs in the nozzle itself, add considerable complexity to the problem.

The following technique was employed to describe the expansion of the neutral gas mixture into vacuum. A source flow analysis (ref. 20) which has demonstrated reasonable agreement with measurements of similar flow fields was adapted. The technique is a modiffed version of Simons' method which describes the density at a given location in the plume in terms of a centerline density which is calculated from continuity relations. Major plume parameters are written in terms of conditions at the nozzle exit and also the boundary layer thickness.

A 1-D, isentropic analysis of the nozzle flow would be invalid in this situation. The arcjet nozzle temperature profile is very steep along the nozzle centerline; however, the majortty of the gas flow passes through the relatively cooler boundary layer. The centerline Mach number will probably be reduced and the viscous nature of the flow will probably lend itself to a very large portion of the boundary layer as being subsonic. For this analysis, experimental performance data were used to obtain nozzle exit properties. The boundary layer thickness was assumed to be $\sim 70$ percent of the exit radius. Conditions at the nozzle throat were calculated using a discharge coefficient of 0.9 and an assumed Mach number of 1 . 


\section{REFERENCES}

1. Curran, F.M. and Haag, T.W., "Arcjet Component Conditions Through a Multistart Test," AIAA Paper 87-1060, May 1987. (NASA TM-89857).

2. Gruber, R.P., "Power Electronics for a 1-k1lowatt Arcjet Thruster," AIAA Paper 86-1507, June 1986. (NASA TM-87340).

3. Hardy, T.L. and Curran, F.M., "Low Power dc Arcjet Operation with Hydrogen/Nitrogen/Ammonia Mixtures," AIAA Paper 87-1948, June 1987. (NASA TM-89876).

4. Haag, T.W. and Curran, F.M., "Arcjet Starting Reliablilty: A Multistart Test on Hydrogen/Nitrogen Mixtures," AIAA Paper 87-1061, May 1987. (NASA TM-89867).

5. "Development of a Plasmajet Rocket Engine for Attitude and Orbit Control," FR-112-651, Plasmadyne Corp., Santa Ana, CA, June 1964. (NASA CR-58268).

6. Van Camp, W.M., et a1, "Analysis of an Arcjet Exhaust," NASA CR-54102, 1964.

7. Van Camp, W.M., et al, "Study of Arc-Jet Propulsion Devices," McDonnell Report E368, McDonneli Aircraft Co., Research Division, St. Louis, MO, Mar. 1966, (NASA CR-54691).

8. Limbaugh, C.C., "Determination of the Excited State Density Distribution Within a Nonequilibrium, Freely Expanding Argon Arcjet Plume," AEDC-TR-77-23, Mar. 1977. (Ava11. NTIS, AD-A037352).

9. Chen, F.F., "Electric Probes," Plasma Diagnostic Techniques, R.H. Hudd leston, and S.L. Leonard, eds., Academic Press, New York, 1965, Chapter 4, pp. 113-200.

10. DeLeeuw, J.H., "Electrostatic Plasma Probes," Physico-Chemical Diagnostics of Plasmas, T.P. Anderson, R.W. Springer, and R.C. Warder, eds., Northwestern University Press, Evanston, IL, 1964, Pp. 65-95. (AIAA Paper 63-370).

11. Chung, P.M.H., Talbot, L., and Touryan, K.J., Electric Probes in Stationary and Flowing Plasma: Theory and Application, Applied Physics and Engineering, Vol. 2, Springer-Verlag, New York, 1975.

12. Laframboise, J.G., "Theory of Spherical and Cylindrical Langmuir Probes in a Collisionless, Maxwellian Plasma at Rest," UTIAS-100, University of Toronto Institute for Aerospaces Studies, June 1964. (Ava11. NTIS, $A D-634596)$.

13. French, J.B., "Langmuir Probes in a Flowing Low Density Plasma," UTIA-79, University of Toronto Institute of Aerophysics, Aug. 1961.

14. Sonin, A.A., "The Behavior of Free Molecule Cylindrical Langmuir Probes in Supersonic Flows, and Their Application to the Study of the Blunt Body Stagnation Layer," UTIAS-109, University of Toronto Institute for Aerospace Studies, Aug. 1965. (Ava11. NTIS, AD-626451). 
15. Clayden, W.A., "Langmuir Probe Studies in the R.A.R.D.E. Plasma Jet," Proceedings of the Third International Symposium on Rarified Gas Dynamics, Vol. 2, J.A. Laurmann, ed., Academic Press, New York, 1962, pp. 435-470.

16. Curran, F.M., NASA Lewis Research Center, Cleveland, OH, Private Communication, May 1987.

17. Beattie, J.R., "Numerical Procedure for Analyzing Langmuir Probe Data," AIAA Journal, Vol. 13, No. 7, July 1975, pp. 950-952.

18. Spitzer, L. Jr., Physics of Fully Ionized Gases, Interscience Publishers, New York, 1956.

19. Sovie, R.J. and Klein, B.M., "Volume Ion Production in a Tenuous Helium Plasma," NASA TN D-2324, 1964.

20. Zana, L.M., Hoffman, D.J., Breyley, L.R., and Serafini, J.S., "An Analytical and Experimental Investigation of Resistojet Plumes," AIAA Paper 87-0399, Jan. 1987. (NASA TM 88852).

TABLE I. - ARCJET THRUSTER DIMENSIONS

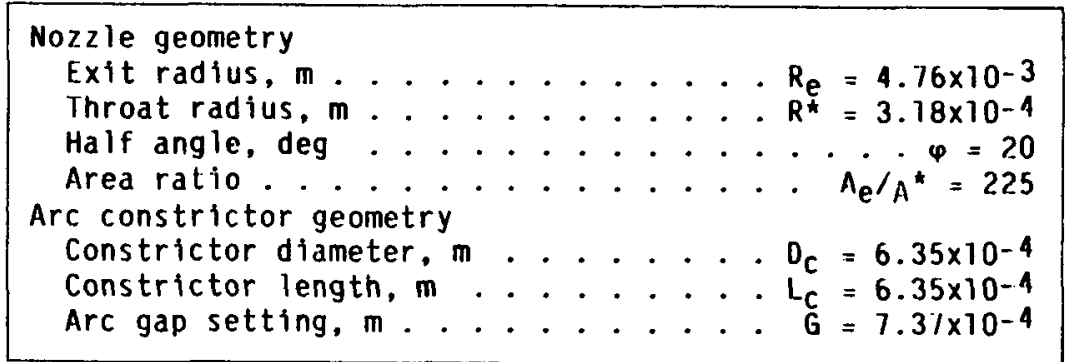

TABIE II. - TYPICAL ARCJET THRUSTER PERFORMANCE CHARACTERISTICS

\begin{tabular}{|l|r|r|r|r|}
\hline $\mathrm{H}_{2}: \mathrm{N}_{2}$ mixture ratio & $2: 1$ & $2: 1$ & $3: 1$ & $3: 1$ \\
$\mathrm{~N}_{2}$ flow rate, slpm & 2.00 & 2.00 & 1.70 & 1.70 \\
$\mathrm{H}_{2}$ flow rate, slpm & 4.00 & 4.00 & 5.10 & 5.10 \\
lotal mass flow rate, g/sec & 0.044 & 0.044 & 0.041 & 0.041 \\
Average molecular weight & 10.6 & 10.6 & 8.5 & 8.5 \\
Inlet pressure, N/m & $4.58 \times 105$ & $4.66 \times 105$ & $4.53 \times 105$ & $4.71 \times 105$ \\
Arc voltage, $\mathrm{V}$ & 93.0 & 95.4 & 95.3 & 92.5 \\
Arc current, $\mathrm{A}$ & 10.0 & 11 & 10 & 12 \\
Arc power, W & 930 & 1049 & 953 & 1110 \\
Thrust, g & 17.3 & 18.0 & 17.0 & 17.6 \\
Specific impulse, sec & 393 & 409 & 414 & 430 \\
Overallefficiency, percent & 34 & 33 & 34 & 32 \\
Cold flow Isp, sec & 114 & 114 & 125 & 125 \\
Cold flow thrust, g & 5.0 & 5.0 & 5.1 & 5.1 \\
\hline
\end{tabular}


TABLE III. - COMPARISON OF LANGMUIR PROBE SIZE VARIATION

[Location: $x=30.5 \mathrm{~cm} ; R=15.2 \mathrm{~cm}$.]

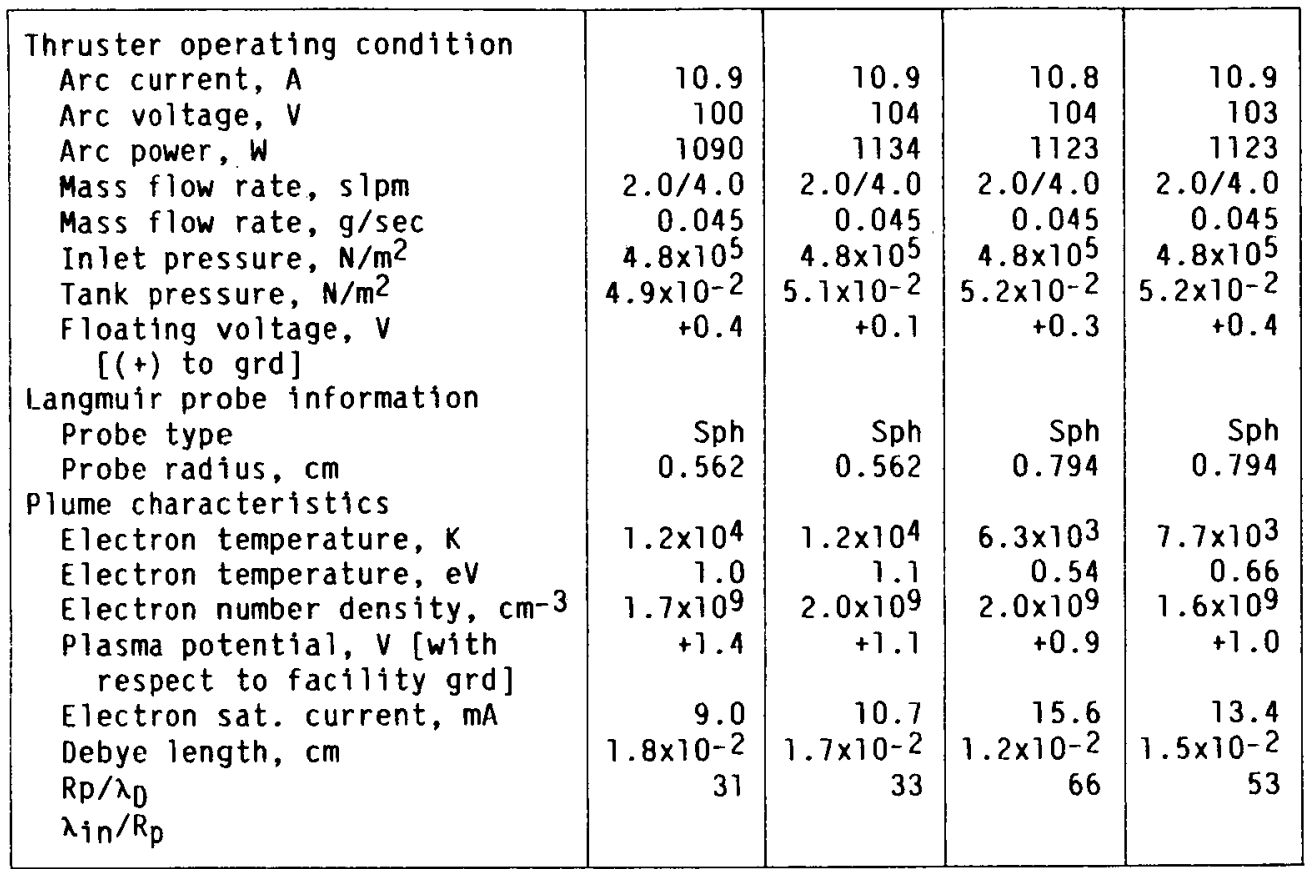

TABLE IV. - COMPARISON OF LANGMUIR PROBE GEOMETRY VARIATION

[Location: $x=18.4 \mathrm{~cm}$; plume centerline.]

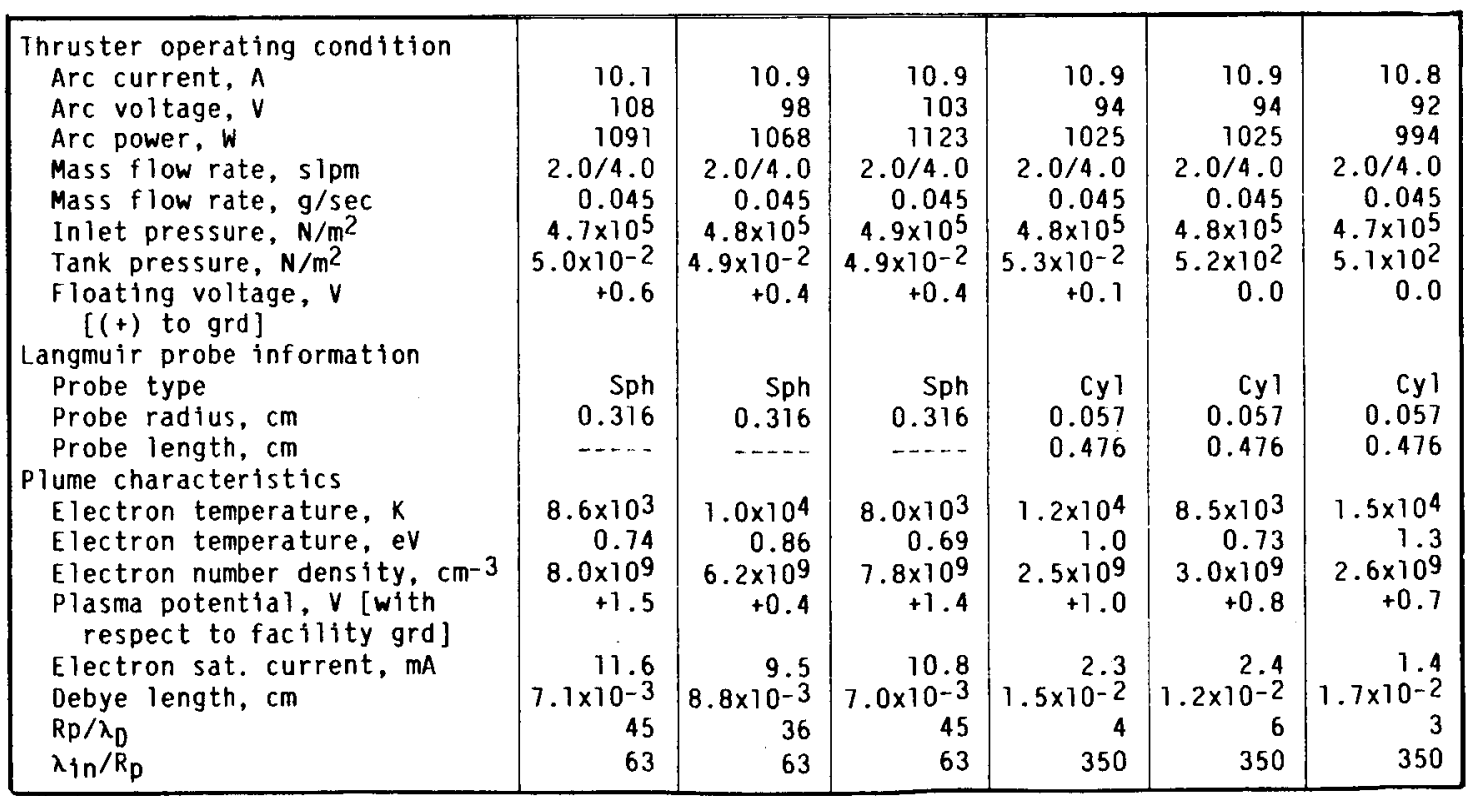


tABle A1. - RELEVANT COLlision PHENOMENA ANO ESTIMATED MEAN fREe PATHS

[Location: Plume centerline, $X=18.4 \mathrm{~cm}$.]

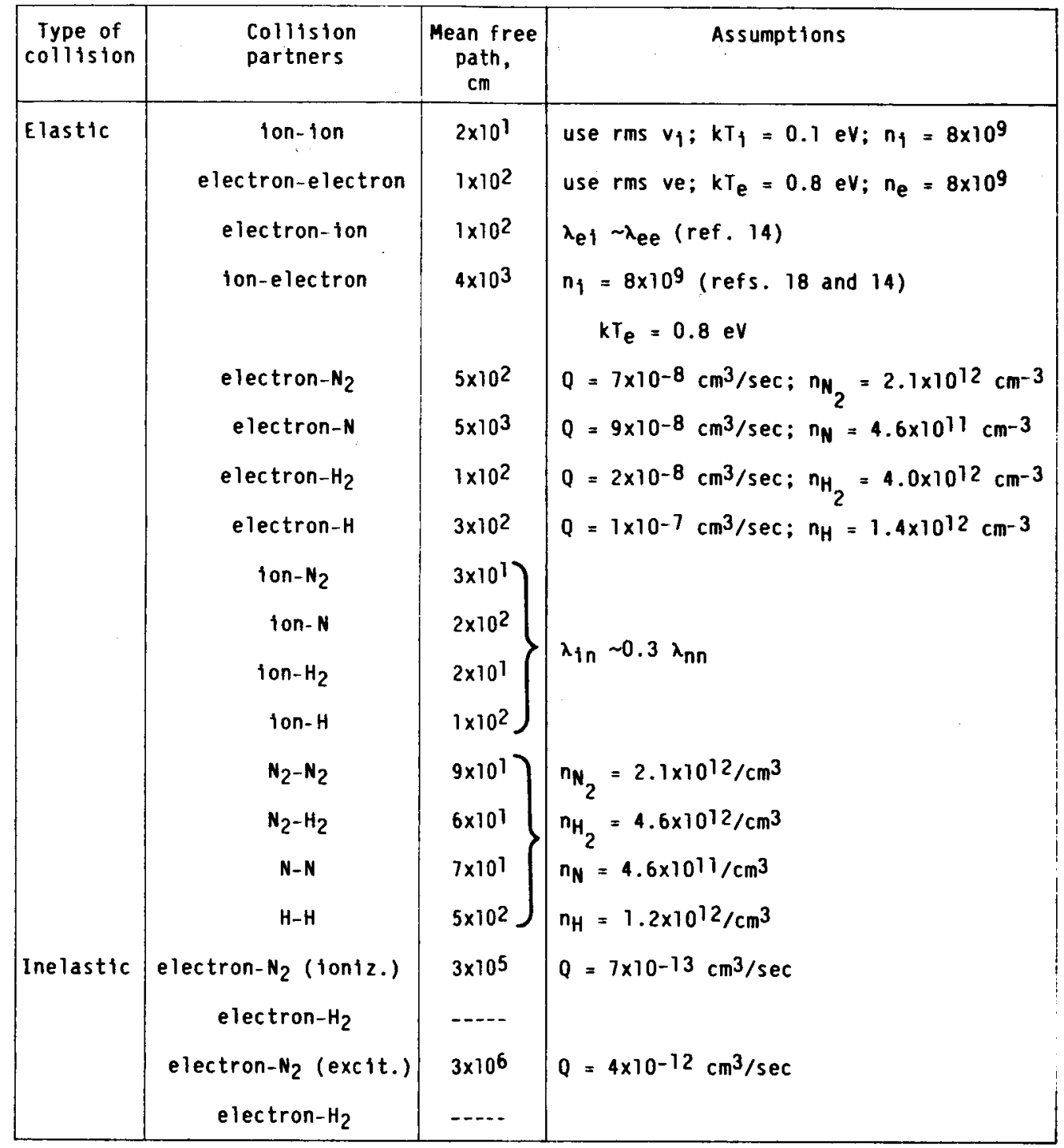


table A2. - RELEVANT COLlision PHENOMENA ano ESTIMATEO MEAN fREe PATHS

[Location: Plume centerline, $X=30.5 \mathrm{~cm}$.]

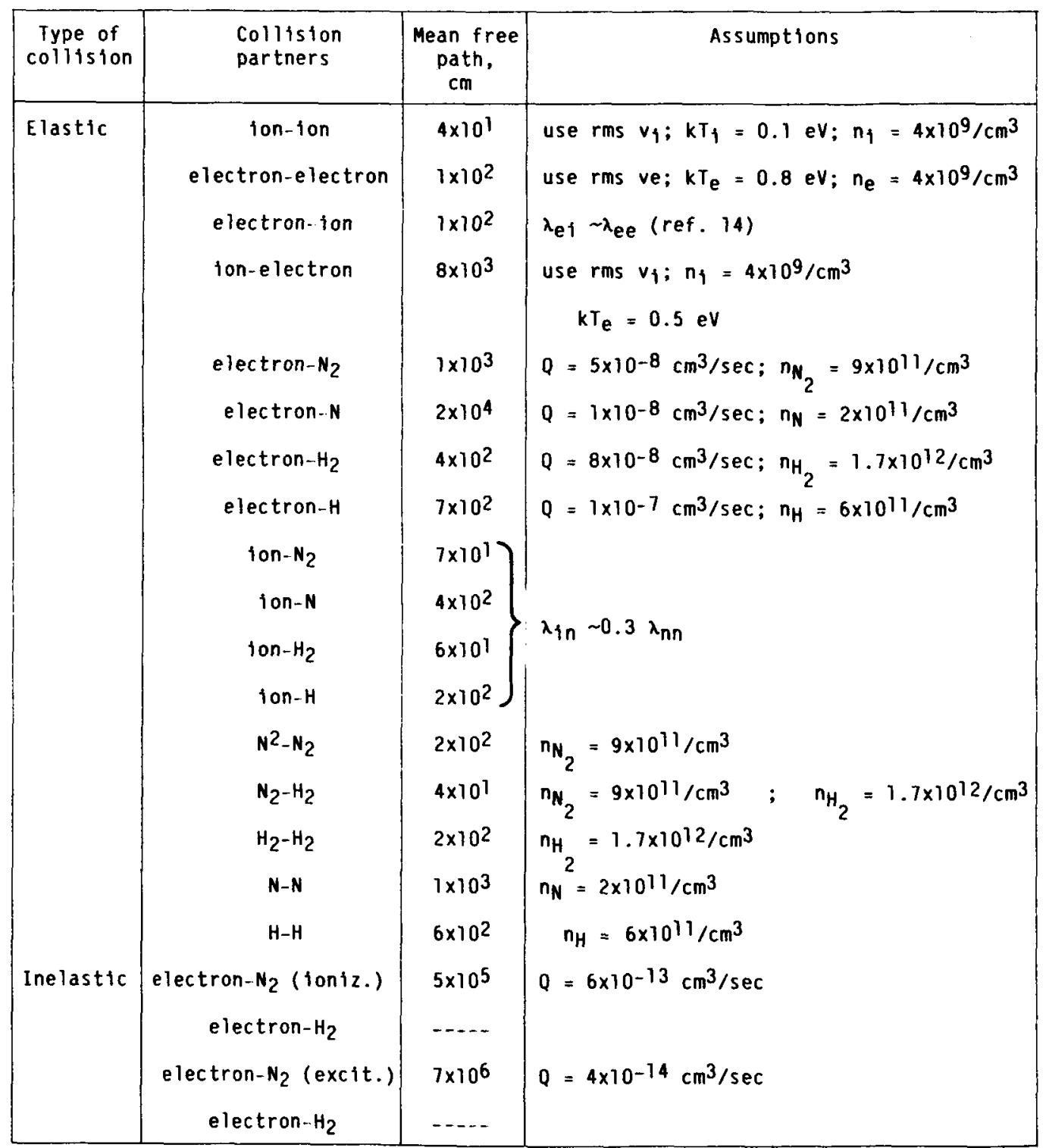




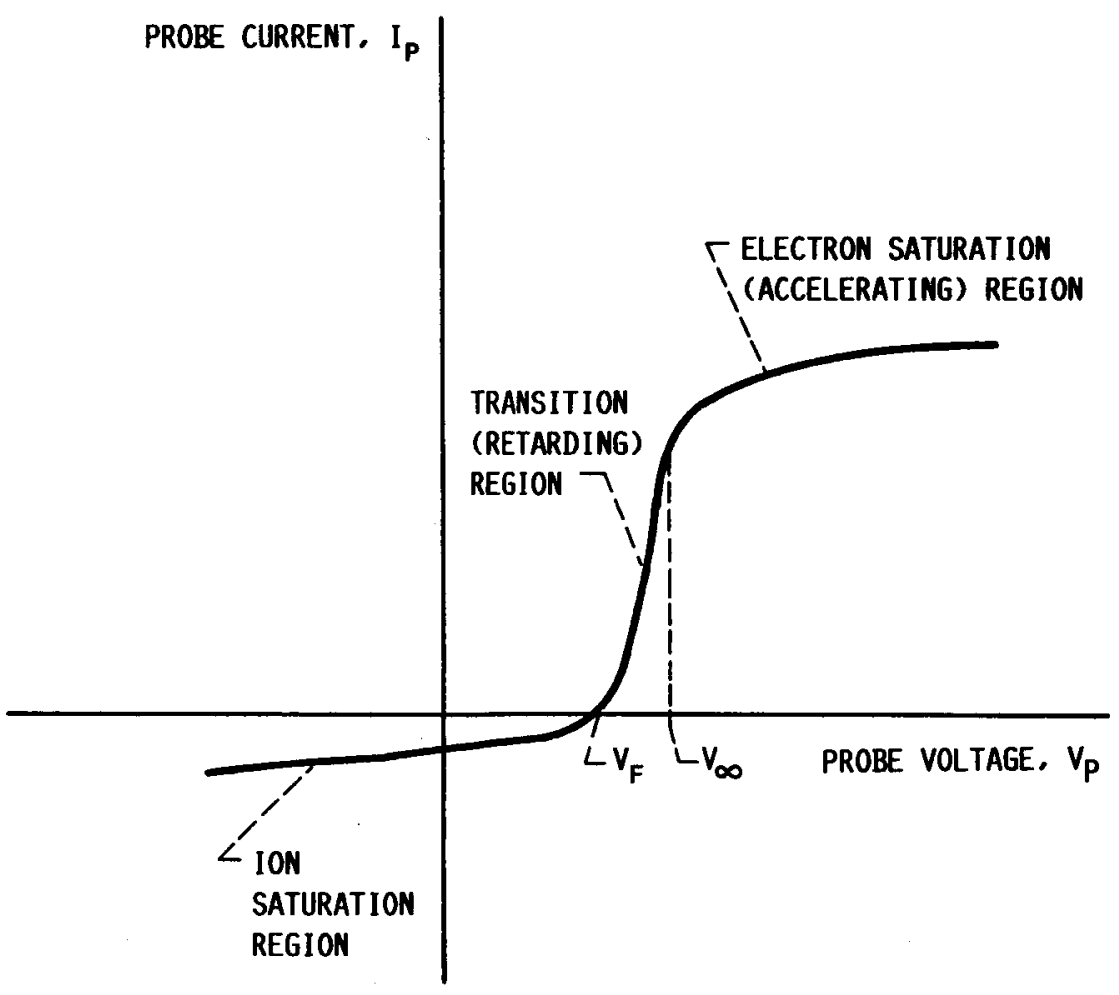

FIGURE 1. - IDEAL LANGMUIR PROBE CHARACTERISTIC WITH RESPECT TO AN ARBITRARY REFERENCE POINT. 


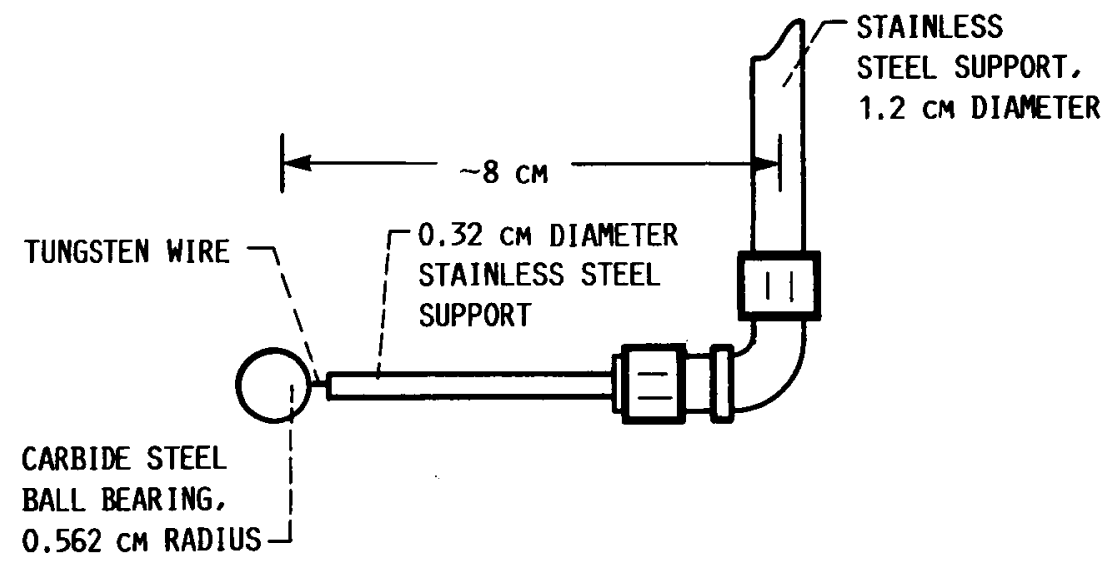

(A) STATIONARY LANGMUIR PROBES.

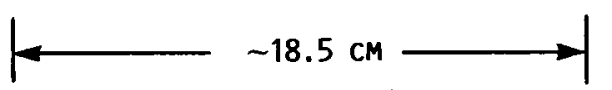

TUNGSTEN WIRE,

$0.057 \mathrm{CM}$ RADIUS

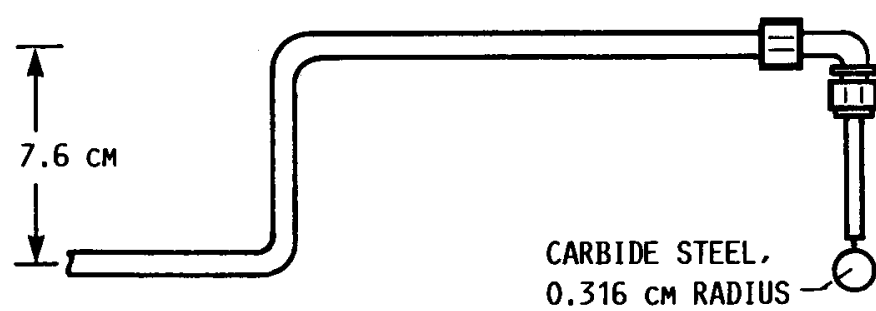

$0.952 \mathrm{cM}$ LENGTH

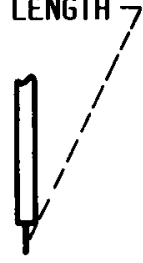

(B) MOVABLE LANGMUIR PROBES OF SPHERICAL AND CYLINDRICAL GEOMETRY. FIGURE 2. - ILLUSTRATIONS OF LANGMUIR PROBE TYPES. 


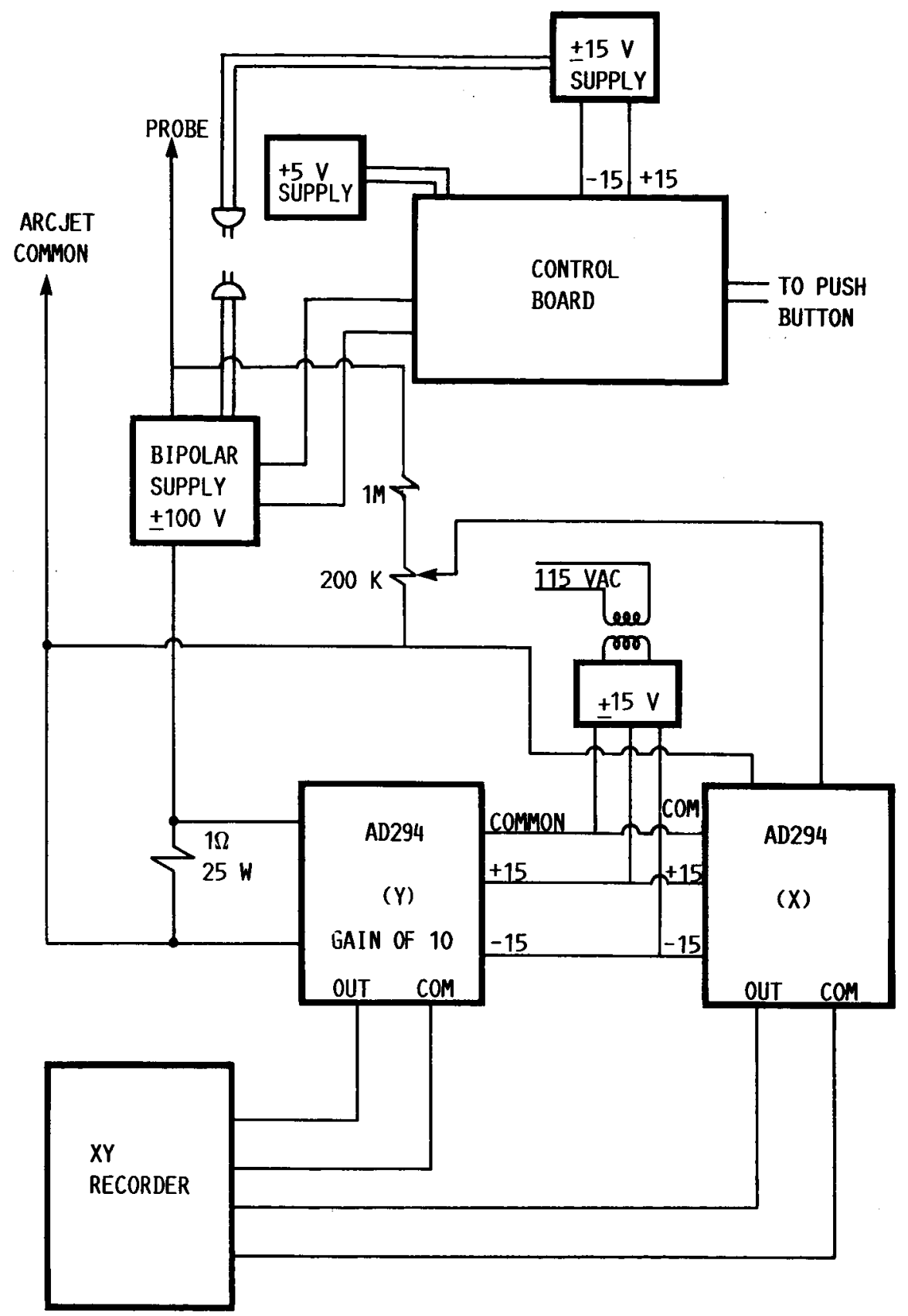

FIGURE 3. - ELECTRICAL SCHEMATIC OF LANGMOIR PROBE DRIVE CIRCUIT AND DATA ACQUISITION. 


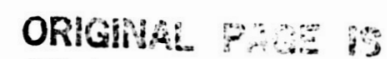

\section{OF POOR QUALTY}

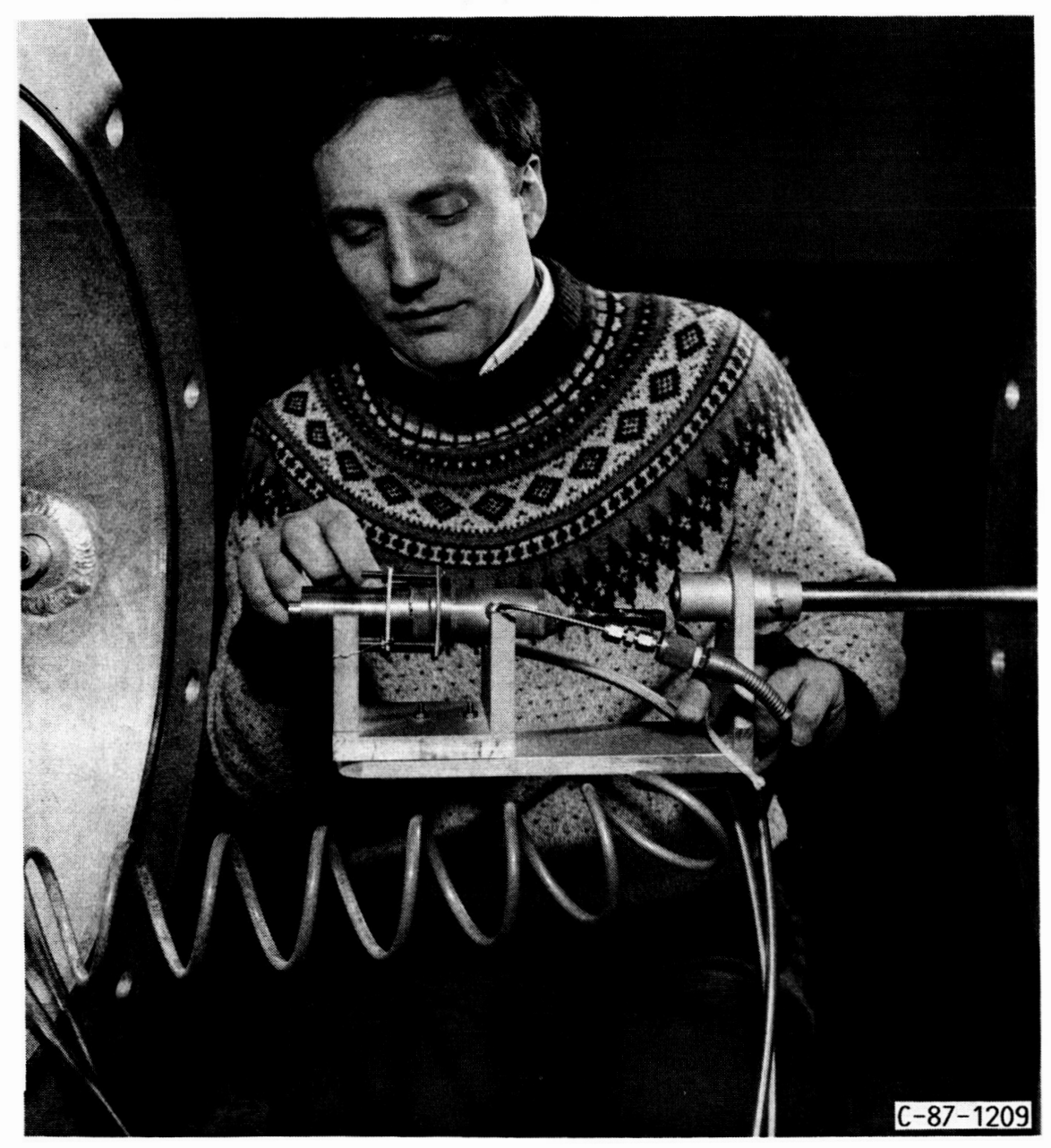

FIGURE 4. - PHOTOGRAPH OF ARCJET THRUSTER MOUNTED ON CRADLE ASSEMBLY. 


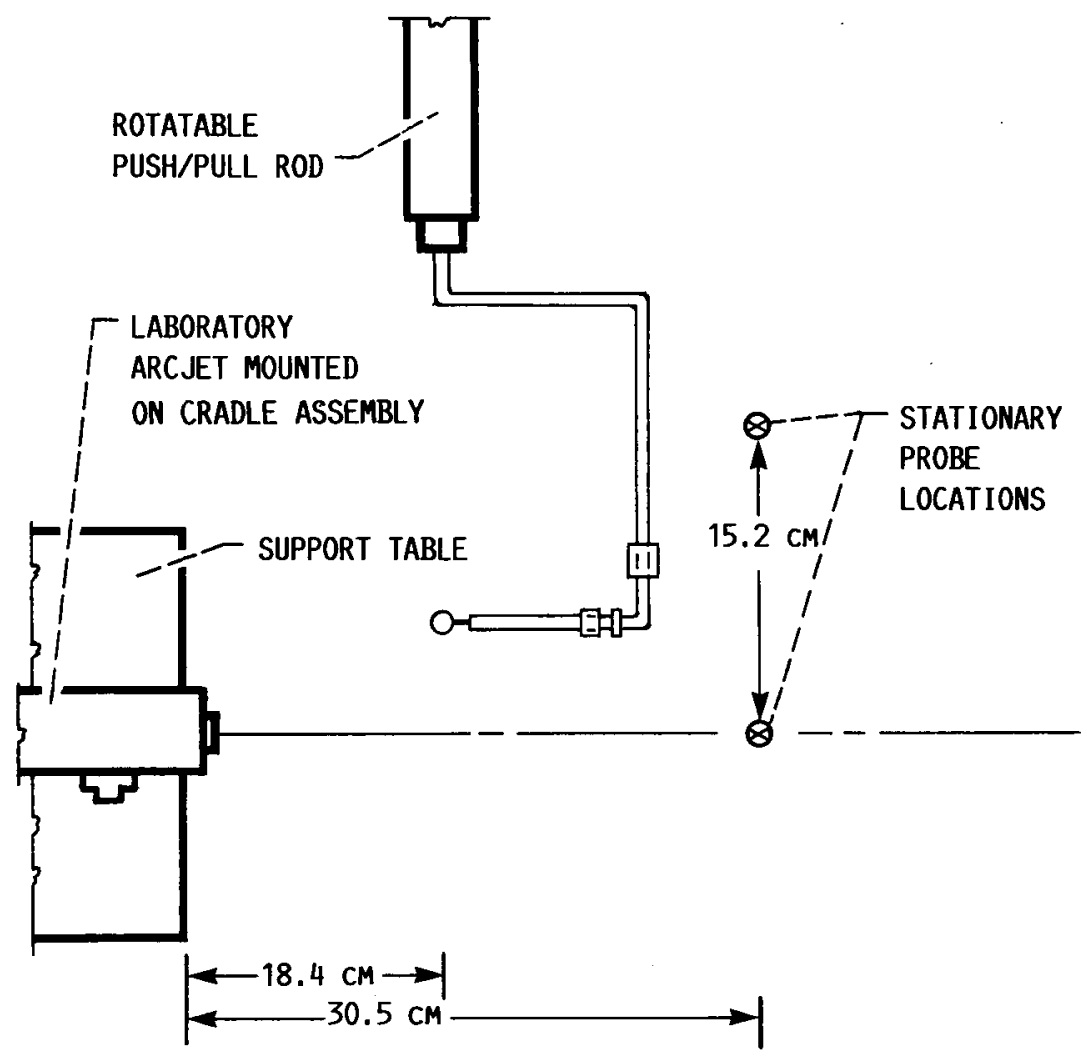

FIGURE 5. - SKETCH OF EXPERIMENTAL SET-UP (TOP VIEW). 


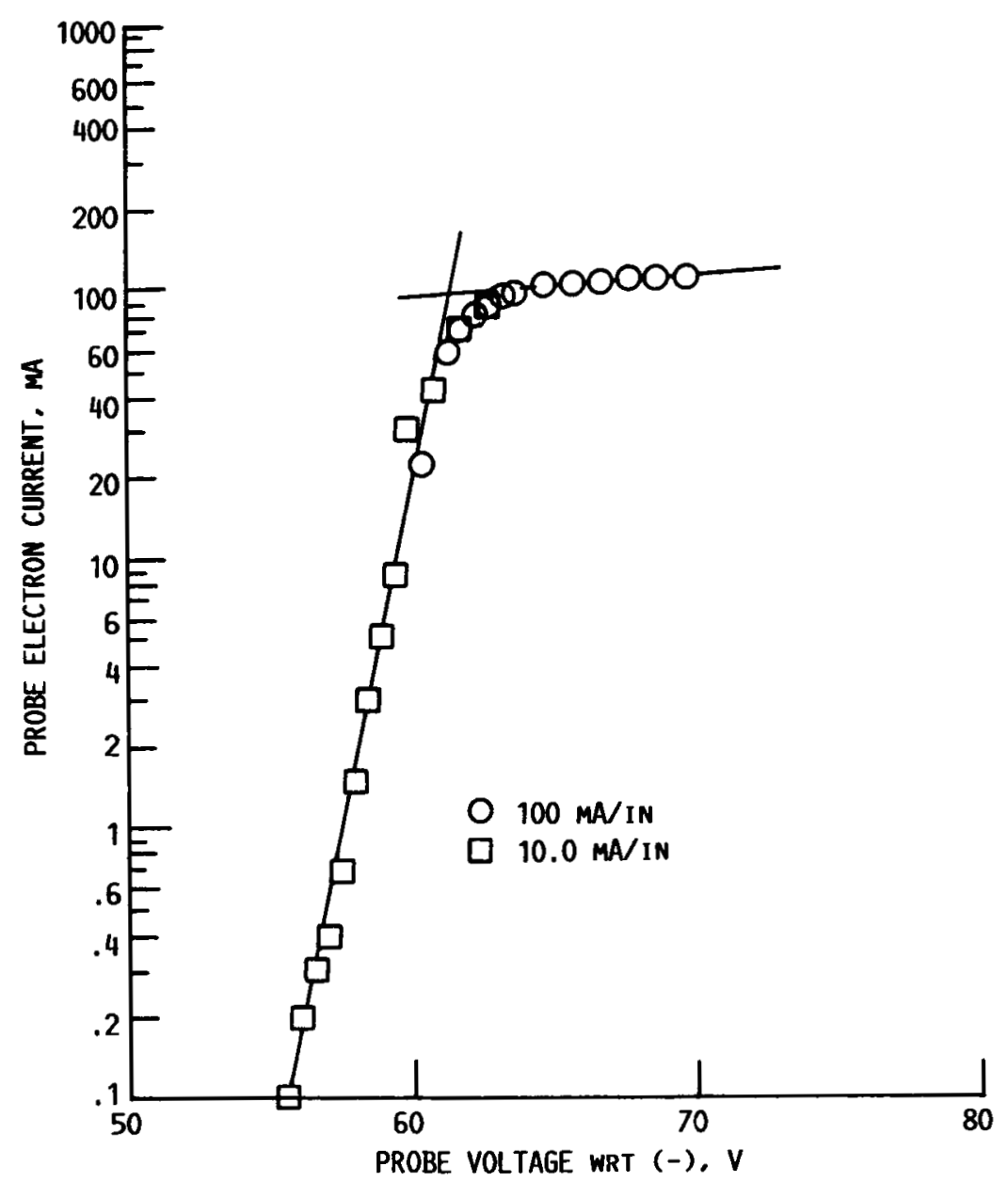

FIGURE 6. - TYPICAL V-I CHARACTERISTIC FOR SPHERICAL PROBE: $x=30.5 \mathrm{~cm}$. PLUME CENTERLINE; ARCJET- $N_{2}$ PROPELLANT. 


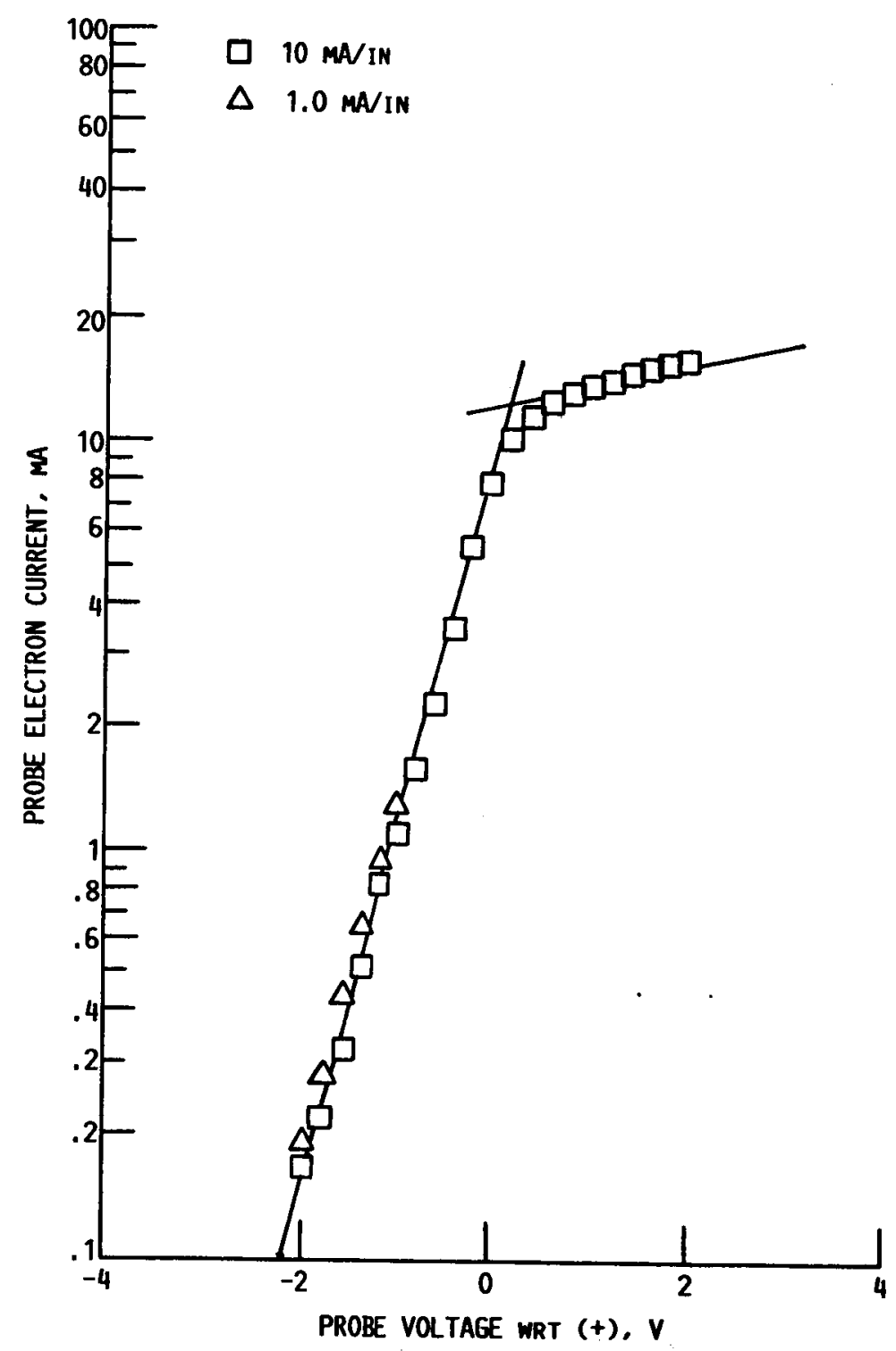

FIGURE 7. - TYPICAL V-I CHARACTERISTIC FOR SPHERICAL PROBE: $x=30.5 \mathrm{~cm}$, PLUME CENTERLINE; $\mathrm{N}_{2}-\mathrm{H}_{2}$ MIXTURE. 


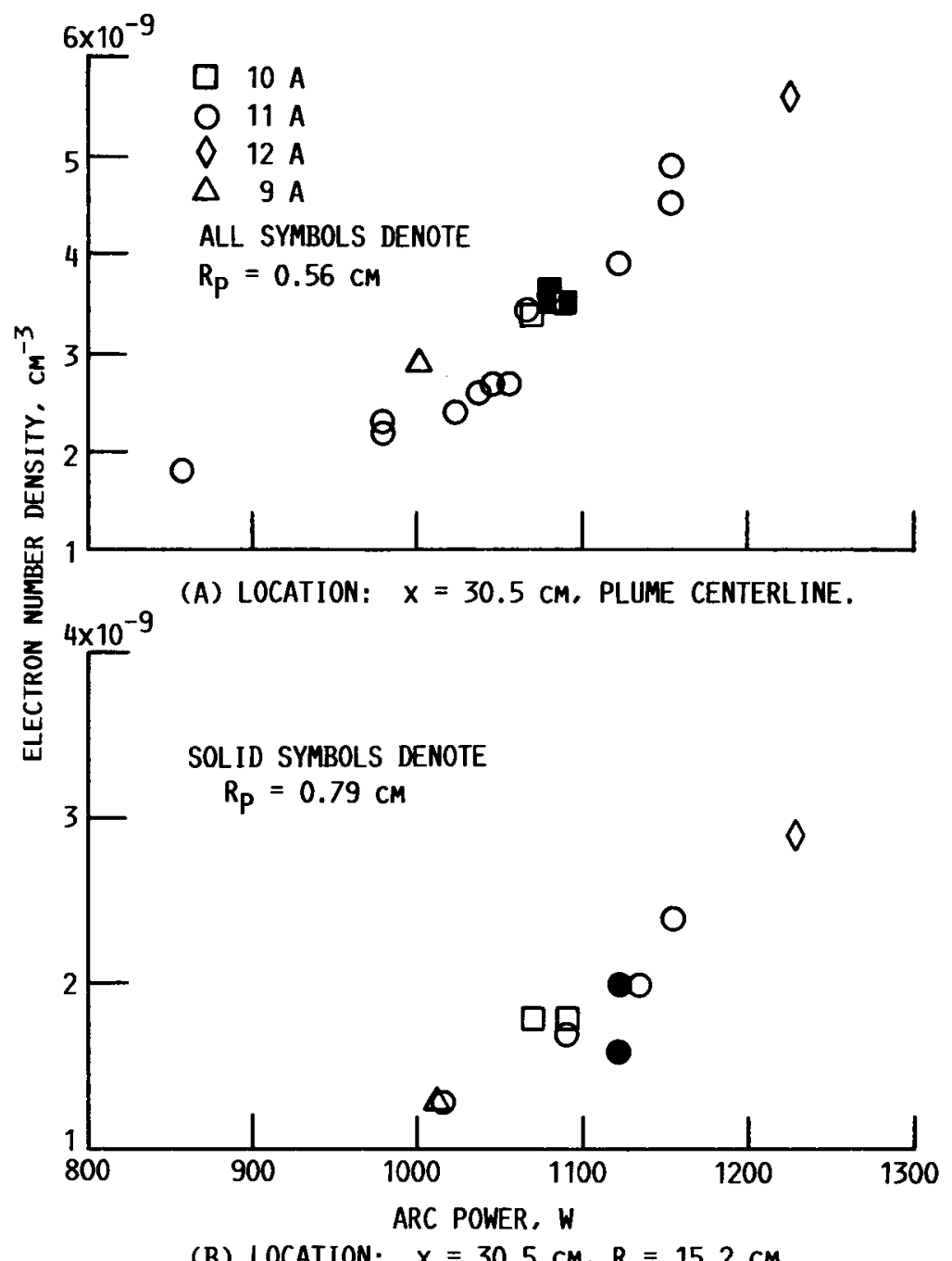

FIGURE 8. - ELECTRON NUMBER DENSITY AS A FUNCTION OF ARC POWER. PROPELLANT: $\mathrm{N}_{2}-\mathrm{H}_{2}$ MIXTURE. 


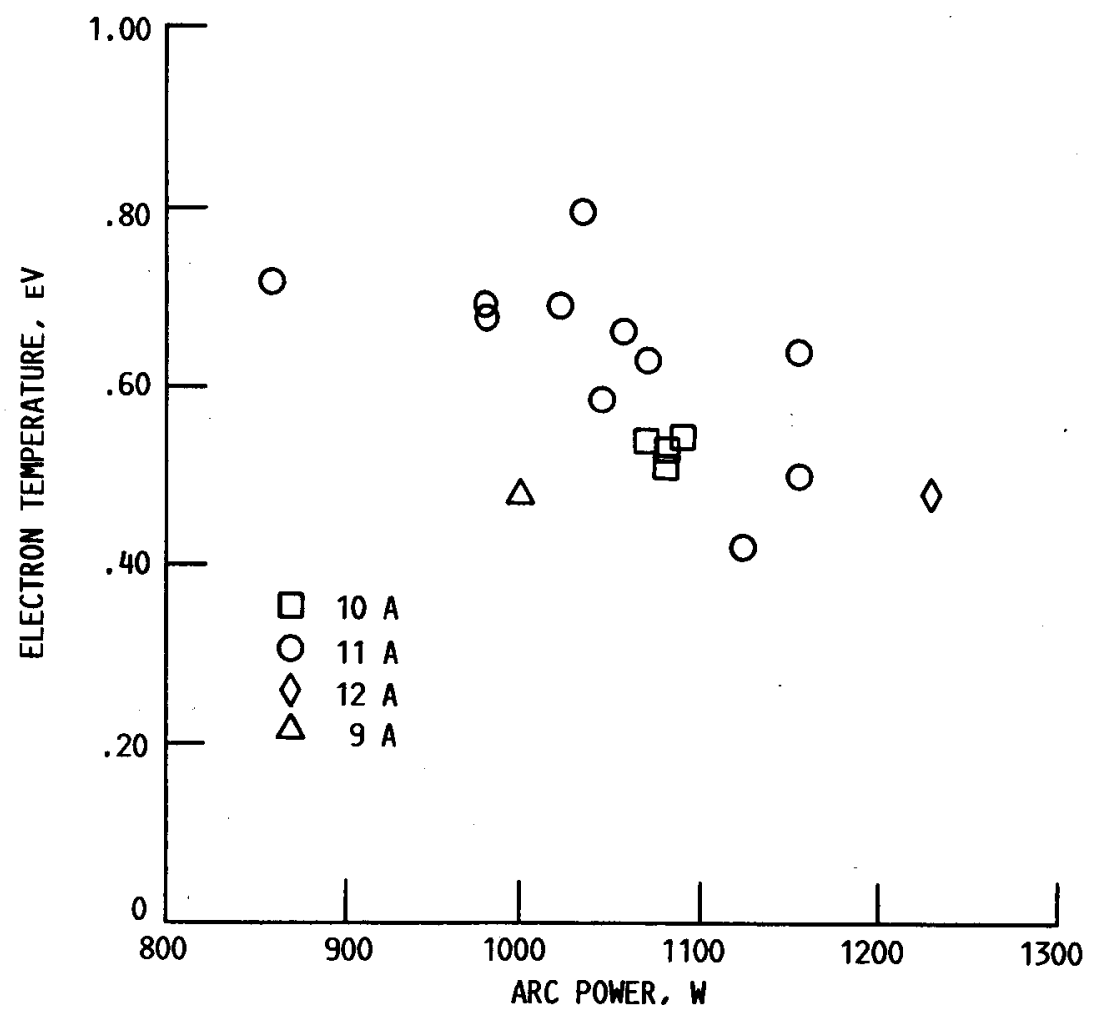

FIGURE 9. - ELECTRON TEMPERATURE AS A FUNCTION OF ARC POHER. LOCATION: $x=30.5 \mathrm{~cm}$, PLUME CENTERLINE. PROPELLANT: $\mathrm{N}_{2}-\mathrm{H}_{2}$ MIXTURE, PROBE RADIUS: $0.562 \mathrm{~cm}$. 


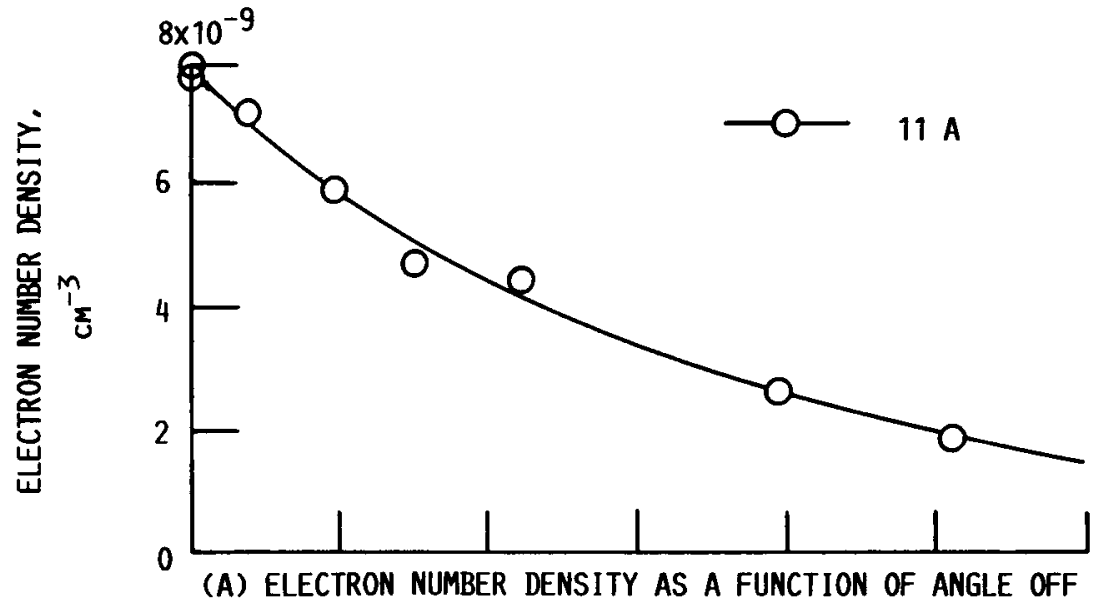
CENTERLINE.

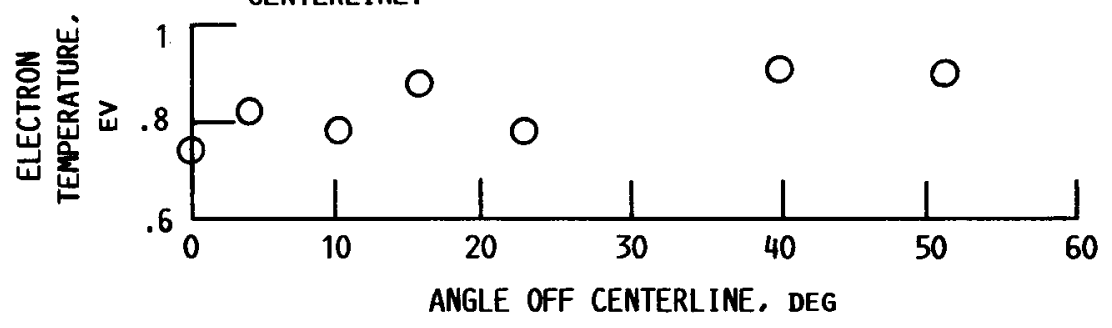

(B) ELECTRON TEMPERATURE AS A FUNCTION OF ANGLE OFF CENTERLINE.

FIGURE 10. - RADIAL PLUME SURVEY AT $x=18.4 \mathrm{~cm}$. PROPELLANT: $\mathrm{N}_{2}-\mathrm{H}_{2}$ MIXTURE: PROBE RADIUS $=0.316 \mathrm{~cm}$. 


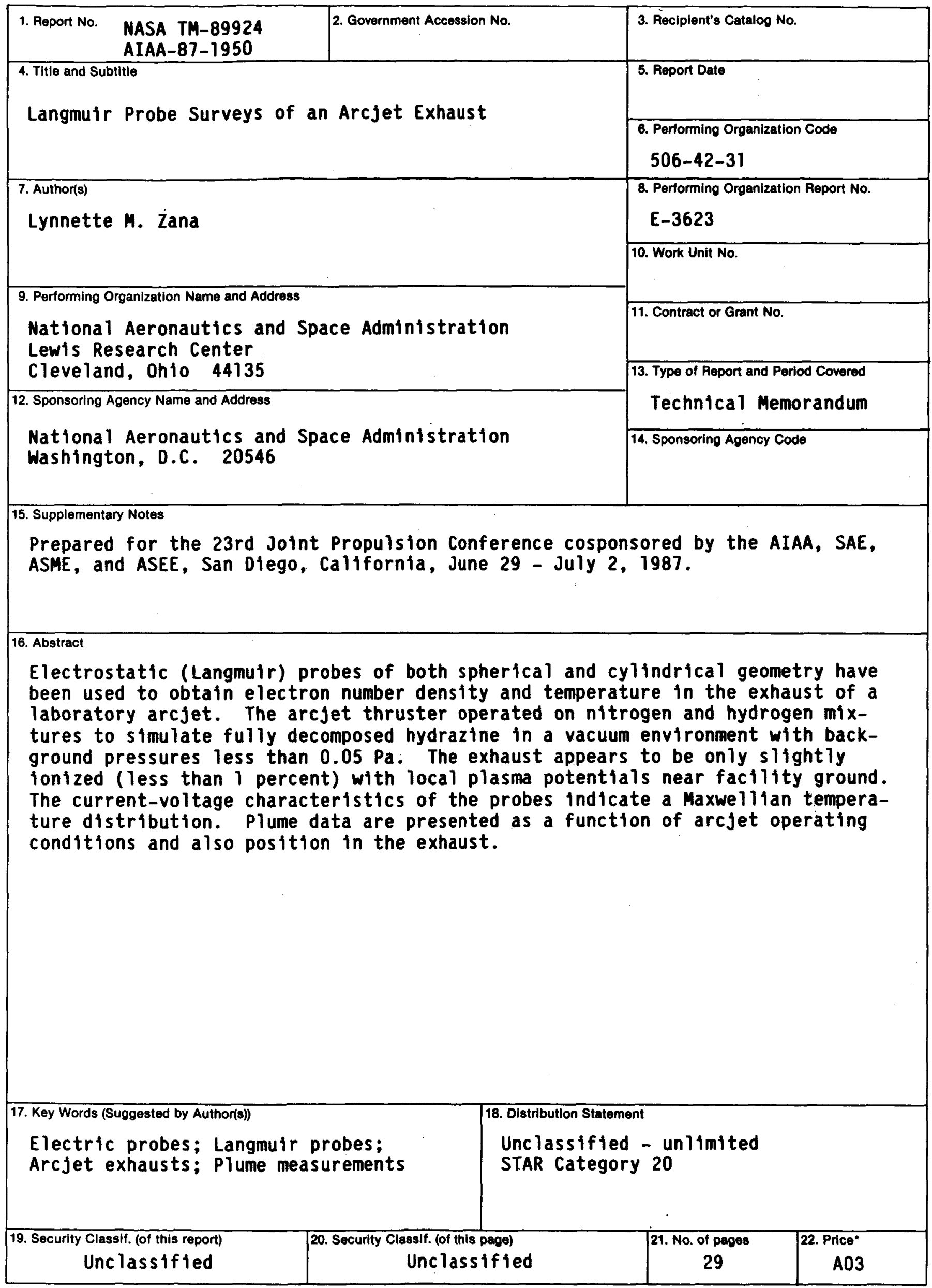

"For sale by the National Technical Information Service, Springfield, Virginia 22161 